\title{
Yoked comparisons of instrumental-avoidance and classical conditioning of the rabbit nictitating membrane response as a function of interstimulus interval and number of trials per day'
}

RALPH B. HUPKA, DOMINIC W. MASSARO, AND JOHN W. MOORE, DEPARTMENT OF PSYCHOLOGY, UNIVERSITY OF MASSACHUSETTS, Amherst, Mass.

Thirty-two albino rabbits were paired in an avoidance-yoke $(A-Y)$ paradigm and received five days of nictitating membrane (NM) conditioning in a 2 by 4 factorial design with interstimulus intervals (ISI) of 250 and 1000 msec crossed with 15, 40, 65, or 90 trials/day. Performance of avoidance Ss was superior to yoked controls only with an ISI of 1000 msec. Failure to obsexve a significant $A-Y$ separation with an ISI of 250 msec was attributed to the uniformly fast conditioning possible with this ISI. Animals receiving a smaller number of trials/day gave more CRs over the first 75 trials and attained the same level of conditioning as the 90 trial/day group. These findings suggest that rabbits consolidate their training overnight.

The purpose of this study was to (a) assess the relative merit of infraorbital shock as the unconditioned stimulus (UCS) in the avoidance-yoke (A-Y) paradigm, (b) determine the optimal number of trials in each daily conditioning session, and (c) evaluate the effect of the CS-UCS interval in the A-Y procedure.

Gormezano, Fuentes, \& Erickson (Gormezano, 1965), in an experiment comparing avoidance rabbits with yoked controls as a function of CS-UCS interval, failed to find a significant overall superiority of avoidance Ss (cf., Moore \& Gormezano, 1961). Since a CR by the yoked $S$ could reduce the noxiousness of an air puff and hence tend to be acquired instrumentally, as in human eyelid conditioning (Prokasy, 1965), a more vivid comparison would seem to dictate the use of a UCS (e.g., electric shock) which cannot be so readily averted by the yoked $S$.

There is some indication that rabbits consolidate their daily training overnight. Conditioned responses of ten appear at the start of a session even though no CRs may have occurred on the previous day (Bruner, 1966; Cholewiak, Hammond, Siegler, \& Papsdorf, 1967). This poses the problem of what constitutes an optimal number of trials per session. Relatively short daily training sessions may provide better CR acquisition than those obtained with long daily training sessions. To allow an assessment of this question 15, 50,65 , or 90 daily trials were given to various groups.

Moore \& Gormezano (1961) have attributed the superior performance of human avoidance $S s$ in comparison to their respective yoked control Ss to the avoidance S receiving the UCS when needed, i.e., when no CR occurs. However, Church (1964) has suggested that the A-Y paradigm contains a bias favoring the instrumental S. A high initial CR probability in an avoidance $S$ supposedly precludes sufficient UCS presentations for conditioning in a yoked $S$ with a low initial conditioning rate. Yet the converse situation of a high initial $C R$ probability in the yoked $S$ does not reduce the number of reinforced trials to the avoidance $S$ and thus enables the latter to condition at his own rate. Church's viewpoint seems to imply that an A-Y separation should be present during the initial conditioning sessions as well as in later stages of training. On the other hand, the Moore and Gormezano position implies that an A-Y difference occurs only later in training because early in training all Ss receive a high percentage of UCS occurrences and it is only later in training, when the rate of UCS occurrences becomes very low, that it is important for the UCS to be presented precisely when needed to counter extinction for the avoidance S. Since the UCS is not necessarily presented to the yoke animal when needed, this permits a degree of extinction of the CR in these Ss which, in turn, results in the A-Y separation. Furthermore, in the framework of Church's argument it would appear that an interstimulus interval(ISI) which is too long slows down a faster instrumental S long enough to allow a slower yoked $S$ to become conditioned. The relatively fast acquisition possible with a $.25 \mathrm{sec}$ ISI (e.g., Schneiderman \& Gormezano, 1964) might also be expected to attenuate individual differences in conditioning rate, and hence eradicate any A-Y effect, whereas a somewhat longer ISI might accentuate the bias. The present study sought to provide direct evidence on these points by employing ISIs of .25 and $1.0 \mathrm{sec}$ and comparing A-Y differences at different stages of conditioning.

Subjects

The Ss were 32 naive, male and female New Zealand White rabbits, 90-120 days old.

\section{Apparatus}

A detailed description of the apparatus and technique for recording from the nictitating membrane (NM) is available elsewhere (Gormezano, 1966). Briefly, a pair of A-Y Ss was run concurrently in two ventilated, illuminated, fireproofed file drawers. Each $\mathrm{S}$ was restrained within a Plexiglas box like those described by Gormezano. The UCS was administered via stainless steel wound clips attached $1 / 8$ in. below and posterior to the eye. A rotary minitorque potentiometer (Giannini No. 85153) was affixed to a headmount. The nylon loop sutured into the NM was connected to the potentiometer so that lateral movement of the NM was amplified and recorded on a Grass 5D oscillograph at a paper speed of 100 $\mathrm{mm} / \mathrm{sec}$. UCS delivery was controlled by a plate circuit relay in series with the negative baseline voltage from the output of the recording power amplifier. Any positive deflection of the response pens of at least $1 \mathrm{~mm}$ during the avoidance interval constituted a CR and resulted in UCS omission. Only avoidance responses occurring no later than $40 \mathrm{msec}$ before UCS onset precluded the UCS $100 \%$ of the time. A motor-pulsed Tally tape transmitter controlled the intertrial interval of 50,60, and $70 \mathrm{sec}$ in a random order with a mean of $60 \mathrm{sec}$, and activated Hunter timers which controlled the CS, UCS, and avoidance interval. The CS was a $1200 \mathrm{~Hz}$ tone ( $70 \mathrm{~dB}$ SPL at the position of S's head) and the UCS a $2 \mathrm{~mA}$ shock of $50 \mathrm{msec}$ duration delivered via the wound clips. On reinforced trials the CS remained on the full 300 or $1050 \mathrm{msec}$ in the respective ISI groups. Procedure

Each A-Y pair was assigned to one cell of a 4 by 2 factorial design combining $15,40,65$, and 90 trials/daily sessions with ISIs of $250 \mathrm{msec}$ and $1000 \mathrm{msec}$. On the day before the first conditioning session the NM was sutured and $S$ was habituated to the apparatus by being placed in the restraining box and remaining in the experimental closure for $1 \mathrm{~h}$. Each pair was given five conditioning days and two extinction sessions.

Results and Discussion

$A-Y$ differences. Figure 1 depicts the mean percentage of CRs over acquisition and extinction days as a function of reinforcement contingency and ISI. As expected, conditioning was better with an ISI of $250 \mathrm{msec}$ than $1000 \mathrm{msec}$. Analysis of variance of per cent CRs in acquisition and extinction showed this difference to be statistically significant: for acquisition, $F=9.66, \mathrm{df}=1 / 8$, $p<.02$; for extinction, $F=10.76, \mathrm{df}=1 / 8, \mathrm{p}<.02$. In addition, a significant interaction effect of ISI by Acquisition Days, $F=5.33, \mathrm{df}=4 / 32, \mathrm{p}<.005$, reflects the faster rate of conditioning obtained with the shorter ISI.

A-Y comparisons revealed that avoidance $S s$ in the $1000 \mathrm{msec}$ ISI condition were superior to their yoked controls only on the last day of acquisition, $t=6.00, d f=7, p<.001$, and both days of extinction, $t=5.50, d f=7$, $p<.001$. The A-Y differences in the $250 \mathrm{msec}$ ISI condition were not significant. Thus the results indicate an A-Y difference only on the last day of training.

A nonmonotonic relationship between ISI and the size of an A-Y separation becomes evident when these findings are contrasted with those reported by Gormezano et al (1965), although the latter study used an air puff UCS. They found higher performance for avoidance Ss with ISIs of 500 and, as in the present study, also with $1000 \mathrm{msec}$ but no difference with $1500 \mathrm{msec}$. Hence, an A-Y separation is possible in the middle range of ISIs but not with ISIs which are too short or too long.

This raises the question as to the basis of the interaction of ISI with the A-Y paradigm. In accordance with our prediction no bias in favor of the avoidance $S$ materialized with an ISI of $250 \mathrm{msec}$. Any advantage that the avoidance S may possess in comparison to its respective yoked control is eliminated with a short ISI because of the relative ease in establishing a fast rate of conditioning in both members of the A-Y pair with only a small number of CS-UCS presentations. The results obtained with an ISI of 1000 msec may reflect the fortuitous pairing of slow learning yoked Ss with fast learning avoidance Ss. However, since no A-Y separation was found early in training the results are also in agreement with the Moore \& Gormezano (1961) notion that only the avoidance $S$ receives the 


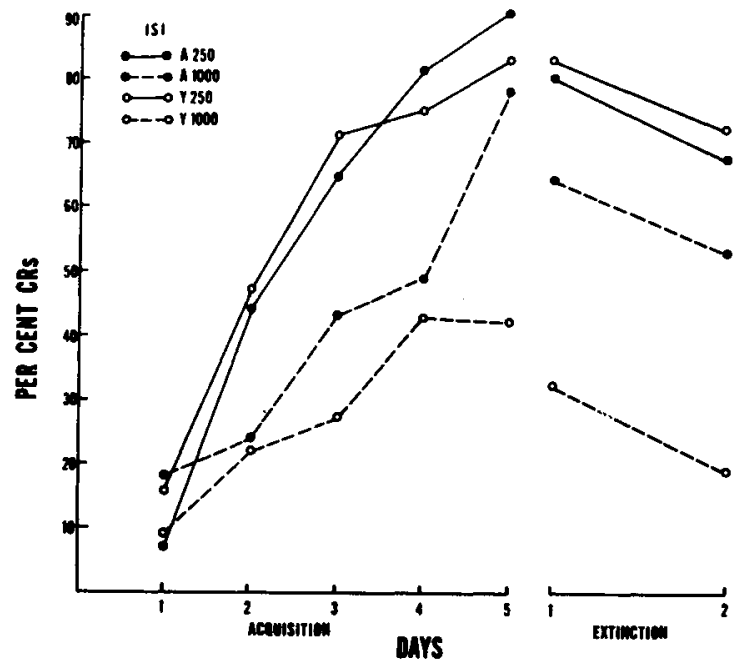

Fig. I. Mean percentage of CRs for the avoid and yoked Ss as a function of days with ISI as the parameter.

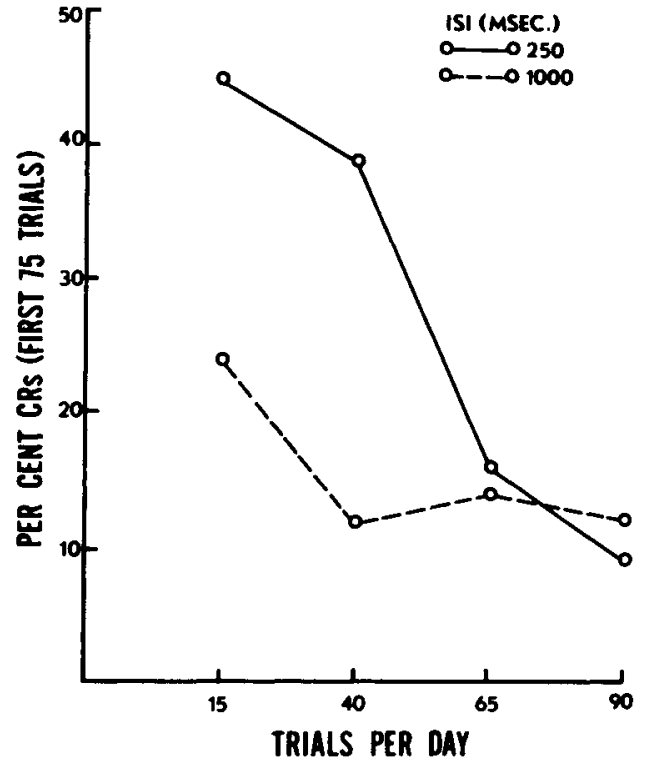

Fig. 2. Mean percentage of CRs for the first 75 trials as a function of the number of training trials per day with ISI as the parameter.

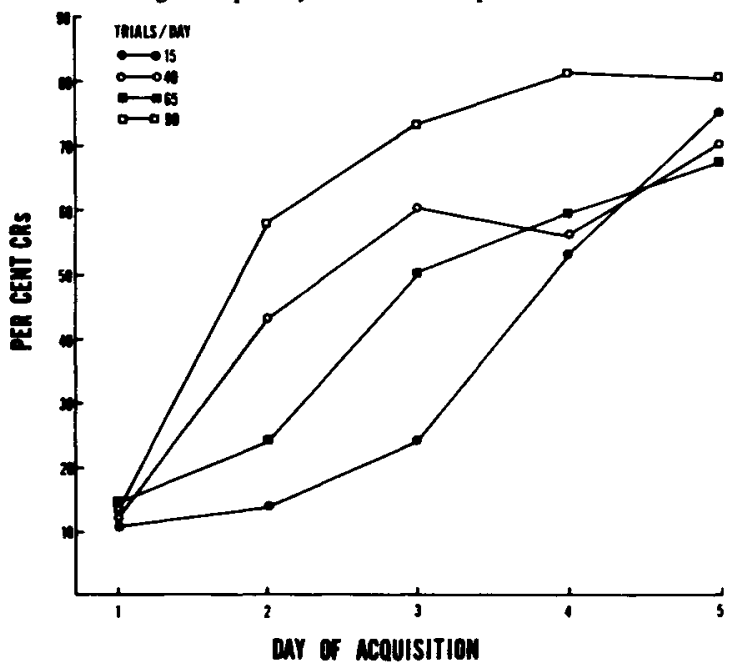

Fig. 3. Mean percentage of CRs as a function of acquisition day with trials/day as the parameter.
UCS when needed, i.e., the A-Y separation is due to the response-event contingency. It is unlikely that the interaction of ISI with initial CR probability of the Ss can readily be resolved with the A-Y paradigm. A more appropriate procedure would be to determine initial CR probability of $S$ s in a conventional conditioning situation with a CS which is different from that to be employed in the A-Y experiment.

Consolidation. Figure 2 shows the mean percentage of CRs during the first 75 trials for each combination of trials/day and ISI. Analysis of variance indicated that the overall linear trend in the data as a function of trials/day was significant, $F=28.00, \mathrm{df}=1 / 8, \mathrm{p}<.001$. The enhancement obtained by spreading the first 75 trials over more sessions was most dramatic with the shorter ISI, and a trend test confirmed the fact that the slopes of the best fitting lines through the two functions in Fig. 2 differed significantly, $F=7.00$, $\mathrm{df}=1 / 8, \mathrm{p}<.05$.

Percentages of CRs for each day of acquisition with trials/day as the parameter are plotted in Fig. 3. Except for an inversion involving the two intermediate groups, acquisition over days was directly related to number of trials/day. For example, the 90 Trials/Day group surpassed the $50 \%$ level on Day 2 whereas the 15 Trials/Day group needed four days to surpass this level. Analysis of variance of the daily percentages of CRs in acquisition indicated that this Day by Trials/Day interaction was significant at the .05 level, $F=2.25$, $\mathrm{df}=12 / 32$. Thus, an investigator wishing to minimize number of sessions rather than number of triais would seem to be better off running more trials/day. Nevertheless, Fig. 3 also suggests a consolidation effect in the substantial gain in performance on Day 2 for the 90 Trials/Day group. In fact, this group gave $44 \%$ CRs over the first 10 trials of Day 2 compared with a $31 \%$ CR rate for the last 10 trials on Day 1 . This $13 \%$ improvement is significant at the .05 level according to a one-tailed test for the difference between two proportions, $z=1.70$. The generality of these findings is limited to the extent that a partial reinforcement schedule, which is in effect as soon as the avoid $S$ is conditioned, is confounded with the trials/day variable. It is unlikely, however, that different results would be obtained with a continuous reinforcement schedule since (a) rabbits generally require a minimum of 50-60 trials for CRs to occur during the first session of conditioning, and (b) the greatest consolidation effect occurs between Day 1 and Day 2.

While the data are not inconsistent with a consolidation hypothesis, they can be interpreted in other terms. For example, the longer sessions may merely have promoted some competing inhibitory process such as reactive inhibition which suppressed early acquisition performance (cf., Fig. 2). But insofar as longer ISIs tend to facilitate inhibition, it would seem that if this interpretation were valid the consolidation effect shown in Fig. 2 should have been more pronounced with the $1000 \mathrm{msec}$ ISI rather than the other way around. Another possibility is that the greater amount of handling necessarily involved in five sessions compared with one or two may have enhanced acquisition rate in the 15 trials/day group without actually involving a time dependent process. It has been our observation that those animals receiving the most handling tend to condition most quickly. But it is difficult to imagine how differential handling alone would interact with ISI to yield the data plotted in Fig. 2. Nevertheless, additional experiments are necessary to eliminate these and other possibilities.

\section{REFERENCES}

BRUNER, A. Facilitation of classical conditioning in rabbits by reinforcing brain stimulation. Psychon. Sci, 1966, 6, 211-212.

CHOLEWIAK, R. W., HAMMOND, R., SIEGLER, I. C., \& PAPSDORF, J. D. Post-trial strychnine facilitation of the classically conditioned nictitating membrane response of the rabbit. Paper read at the Midwestern Psychological Association, Chicago, May, 1967.

CHURCH, R. M. Systematic effect of random error in the yoked control design. Psychol. Bull, 1964, 62, 122-131.

GORMEZANO, I. Classical conditioning. In J. B. Sidowski(Ed.), Experimental methods and instrumentation in psychology. New York: McGraw-Hill, 1966. Pp. 385-420.

GORMEZANO, I. Yoked comparisons of classical and instrumental conditioning of the eyelid response; and an addendum on "voluntary re sponders." In W. F. Prokasy (Ed.), Classical conditioning. New York: AppletonCentury-Crofts, 1965.Pp.48-70.

MOORE, J. W., \& GORMEZANO, I. Yoked comparisons of instrumental and classical eyelid conditioning.J. exp. PsychoL, 1961, 62, 552-559.

PROKASY, W. F. Classical eyelid conditioning: experimenter operations, task demands, and response shaping. In W. F. Prokasy (Ed.), Classical conditioning. New York: Appleton-Century-Crofts, 1965. Pp. 208-225.

SCHNEIDERMAN, N., \& GORMEZANO, I. Conditioning of the nictitating membrane of the rabbit as a function of CS-US interval.J. comp. physiol. Psychol, 1964, 57, 188-195.

\section{NOTE}

1. This investigation was supported in part by NSF Grant GB-5480. 